\title{
Artificial Neural Networks: Applications In Management
}

\author{
Ayushi Sharma ${ }^{1}$, Akshit Chopra ${ }^{2}$ \\ ${ }^{I}$ (Department Of Computer Science, Maharaja Surajmal Institute Of Technology - Guru Gobind Singh \\ Indraprastha University, India) \\ ${ }^{2}$ (Department Of Computer Science, Maharaja Surajmal Institute Of Technology - Guru Gobind Singh \\ Indraprastha University, India)
}

\begin{abstract}
With the advancement of computer and communication technology, the tools used for management decisions have undergone a gigantic change. Finding the more effective solution and tools for managerial problems is one of the most important topics in the management studies today. Artificial Neural Networks (ANNs) are one of these tools that have become a critical component for business intelligence. The purpose of this article is to describe the basic behavior of neural networks as well as the works done in application of the same in management sciences and stimulate further research interests and efforts in the identified topics.
\end{abstract}

Key words: Artificial Neural Networks, Management Applications, Management, Marketing

\section{Introduction}

CLASSIFICATION is one of the most frequently encountered decision making tasks of human activity. A classification problem occurs when an object needs to be assigned into a predefined group or class based on a number of observed attributes related to that object. Many problems in business, science, industry, and medicine can be treated as classification problems. Examples include bankruptcy prediction, credit scoring, medical diagnosis, quality control, handwritten character recognition, and speech recognition. Neural networks have emerged as an important tool for classification. Neural networks have seen an explosion of interest over a last few years and are being successfully applied across an extraordinary range of problem domains. The excitement stems from the fact that these networks are attempts to mimic the capabilities of the human brain.

Artificial neural networks are distributed information processing systems composed of many simple computational elements interacting across weighted connections. ANNs can identify and learn correlated patterns between input data sets and corresponding target values. After training, ANNs can be used to predict the outcome of new independent input data. ANNs seek to simulate the human brain structure, human thinking and human learning in a machine. Thus they are ideally suited for the modeling of agricultural data which are often complex and non linear.

These networks are "neural" in the sense that they have been inspired by neuroscience but not necessarily because they are faithful models of biological cognitive phenomena. The majority of the networks are closely related to traditional mathematical and statistical models such as clustering algorithms, non linear filters etc.

An ANN consists of many single processors, which interact through a dense web of interconnections. A neuron or processing element has primarily two things to do. One is that it computes output which is sent to another neuron which determines its output value by applying a transfer function. Two, it updates the local memory, i.e. weights and other data types called data variables. These processing elements are organized into two layers. The first layer is known as the input layer and the last layer is referred to as the output layer. The one or more inner layers are known as hidden layers. The input neurons receive values from outside the neural networks' environment, whereas the output neurons send the values to this outside environment.

\section{Characterictics Of Neural Networks}

$>$ The NNs exhibit mapping capabilities hence they can map their input patterns to the associated output patterns.

$>$ Since the NNs learn by examples, the NN architecture can be trained with known examples of a problem before they are tested for their inference capability on unknown instances of the problem.

$>$ They possess the capability to generalize.

$>$ They are robust systems and fault tolerant and hence they can recall full patterns from incomplete, partial or noisy patterns.

$>$ They can process information in parallel at high speed and in a distributed manner.

$>$ They can be used to cluster the training data into natural groups based on the similarity of characteristics in the training data. 


\section{Neural Networks: Basics}

The terminology of artificial neural networks has developed from a biological model of the brain. A neural network consists of a set of connected cells: The neurons. The neurons receive impulses from either input cells or other neurons and perform some kind of transformation of the input and transmit the outcome to other neurons or to output cells. The neural networks are built from layers of neurons connected so that one layer receives input from the preceding layer of neurons and passes the output on to the subsequent layer.

The neuron is a real function of the input vector $\left(y_{1}, \ldots ., y k\right)$. The output is obtained as $f\left(x_{j}\right)=f\left(\alpha_{j}+\right.$ $\sum_{\mathrm{i}=1}^{\mathrm{k}} \mathrm{W}_{\mathrm{ij}} \mathrm{y}_{\mathrm{j}}$ ), where $\mathrm{f}$ is a function, typically a sigmoid function. A graphical presentation of neuron in the figure below:

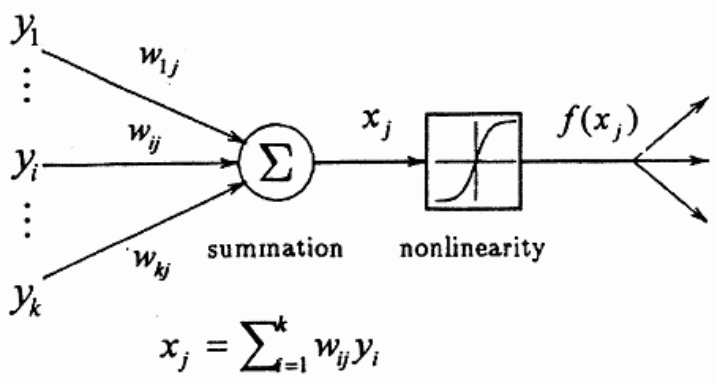

\section{Neural networks architectures}

Figure 1 : a simple neuron

An ANN is defined as a data processing system consisting of a large number of simple highly inter connected processing elements (artificial neurons) in an architecture inspired by the structure of the cerebral cortex of the brain. There are several types of architecture of NNs. However, the two most widely used NNs are discussed below:

\section{Feed forward networks}

In a feed forward network, information flows in one direction along connecting pathways, from the input layer via the hidden layers to the final output layer. There is no feedback

(Loops) i.e., the output of any layer does not affect that same or preceding layer.

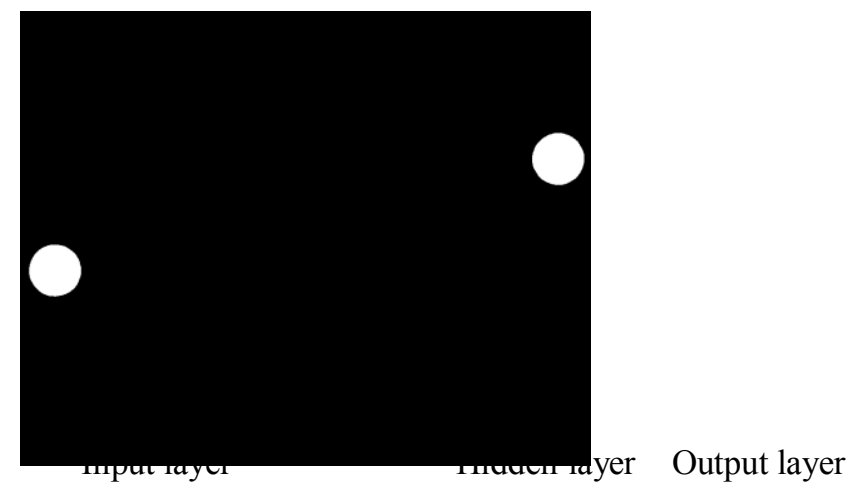

Figure 2: A multi-layer feed forward neural network

\section{Recurrent networks}

These networks differ from feed forward network architectures in the sense that there is at least one feedback loop. Thus, in these networks, for example, there could exist one layer with feedback connections as shown in figure below. There could also be neurons with self- feedback links, i.e. the output of a neuron is fed back into itself as input. 


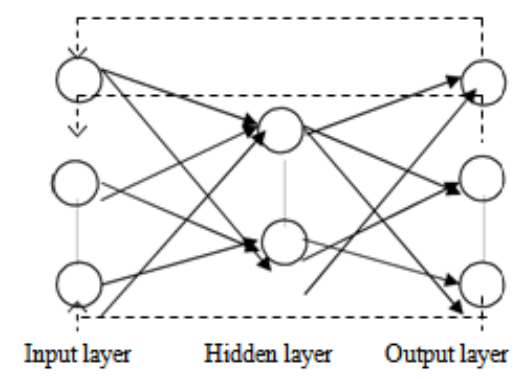

Figure 3: A recurrent neural network

\section{Learning/Training methods}

Learning methods in neural networks can be broadly classified into three basic types: supervised, unsupervised and reinforced.

\section{Supervised learning}

In this, every input pattern that is used to train the network is associated with an output pattern, which is the target or the desired pattern. A teacher is assumed to be present during the learning process, when a comparison is made between the network's computed output and the correct expected output, to determine the error. The error can then be used to change network parameters, which result in an improvement in performance.

\section{Unsupervised learning}

In this learning method, the target output is not presented to the network. It is as if there is no teacher to present the desired patterns and hence, the system learns of its own by discovering and adapting to structural features in the input patterns.

\section{Reinforced learning}

In this method, a teacher though available, does not present the expected answer but only indicates if the computed output is correct or incorrect. The information provided helps the network in its learning process. A reward is given for a correct answer computed and a penalty for a wrong answer. But, reinforced learning is not one of the popular forms of learning.

\section{Types of neural networks}

The most important class of neural networks for real world problems solving includes

- Multilayer Perceptron

- Radial Basis Function Networks

- Kohonen Self Organizing Feature Maps

\section{Multilayer Perceptrons}

The most popular form of neural network architecture is the multilayer perceptron (MLP). A

multilayer perceptron:

- has any number of inputs.

- has one or more hidden layers with any number of units.

- uses linear combination functions in the input layers.

- uses generally sigmoid activation functions in the hidden layers.

- has any number of outputs with any activation function.

- has connections between the input layer and the first hidden layer, between the hidden

layers, and between the last hidden layer and the output layer.

Given enough data, enough hidden units, and enough training time, an MLP with just one hidden layer can learn to approximate virtually any function to any degree of accuracy. (A statistical analogy is approximating a function with $n$th order polynomials.) For this reason MLPs are known as universal approximators and can be used when you have little prior knowledge of the relationship between inputs and targets. Although one hidden layer is always sufficient provided you have enough data, there are situations where a network with two or more hidden layers may require fewer hidden units and weights than a network with one hidden layer, so using extra hidden layers sometimes can improve generalization. 


\section{Radial Basis Function Networks} network:

Radial basis functions (RBF) networks are also feed forward, but have only one hidden layer. A RBF

- $\quad$ has any number of inputs.

- typically has only one hidden layer with any number of units.

- uses radial combination functions in the hidden layer, based on the squared Euclidean

distance between the input vector and the weight vector.

- typically uses exponential or softmax activation functions in the hidden layer, in which case the network is a Gaussian RBF network.

- has any number of outputs with any activation function.

- has connections between the input layer and the hidden layer, and between the hidden

layer and the output layer.

MLPs are said to be distributed-processing networks because the effect of a hidden unit can be distributed over the entire input space. On the other hand, Gaussian RBF networks are said to be localprocessing networks because the effect of a hidden unit is usually concentrated in a local area centered at the weight vector.

\section{Kohonen Neural Network}

Self Organizing Feature Map (SOFM, or Kohonen) networks are used quite differently to the other networks. Whereas all the other networks are designed for supervised learning tasks, SOFM networks are designed primarily for unsupervised learning (Patterson, 1996).

At first glance this may seem strange. Without outputs, what can the network learn? The answer is that the SOFM network attempts to learn the structure of the data. One possible use is therefore in exploratory data analysis. A second possible use is in novelty detection. SOFM networks can learn to recognize clusters in the training data, and respond to it. If new data, unlike previous cases, is encountered, the network fails to recognize it and this indicates novelty. A SOFM network has only two layers: the input layer, and an output layer of radial units (also known as the topological map layer).

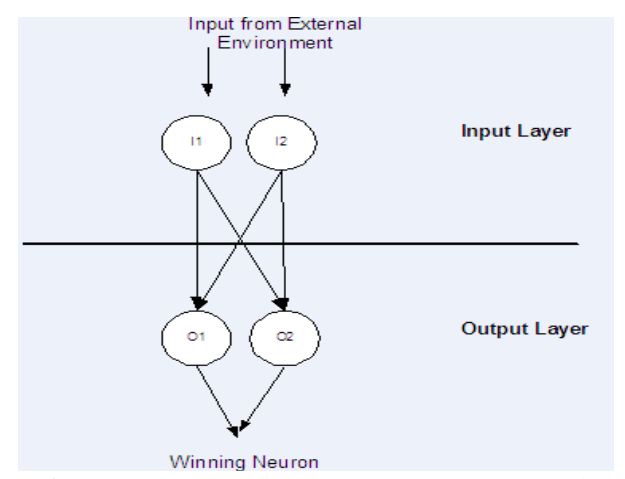

Figure 4: A Kohonen Neural Network Applications

\section{Applications In The Field Of Marketing:}

ANN can be applied to many marketing decision problems which could previously be tackled only by multivariate statistical analysis. Typical problems are market segmentation tasks and market response modeling, consumer spending patterns, new product analysis, identification of customer characteristics; targeted marketing etc. the most crucial point for research activities in the field of marketing is the lack of applications on the individual level data.

These kinds of problems are encountered in the context of purchase behavior in the tradition of stochastic models of consumer behavior.

\section{Applications In The Field Of Finance:}

Artificial neural networks are frequently used in many modeling and forecasting problems, mainly due to the chances of use of computer intensive methods. Recently, they have been increasingly applied in the financial time series analysis. The main advantage of the same is the ability to approximate almost any nonlinear function arbitrarily close. ANNs can provide a better fit particularly in financial time series with complex non linear dynamic relationships. However, it is usually difficult to interpret the meaning of the parameters and the neural networks are seen as "black box" models constructed for the pattern recognition and prediction. The essential topics in finance are the forecasts of changes in the value of financial assets under the form of stocks, currencies, analysis of strength of historical financial statements. 
Applications In The Field Of Manufacturing And Production:

Forecasting i.e. production costs, delivery dates etc., quality control and optimization dominates the production problems. As quality control problems correspond to classification thus the appropriateness of the application of artificial neural networks is supposed to be as good as those in the fields of finance and marketing.

\section{Applications In The Field Of Strategic Mangement And Business Policy:}

The research in strategic planning systems is focused on two areas namely the impact of strategic planning on firm performance and the role of strategic planning in strategic decision making. ANN as efficient tool have been utilized for determining and clarifying the relationship between strategic planning and performance and also assessing decision making.

Table: Reported Applications of Artificial Neural Networks

\begin{tabular}{|c|c|c|}
\hline Business Area & Problem type & neference \\
\hline \multirow[t]{20}{*}{ Marketing and Sales } & Forecasting costumer respond & {$\left[\begin{array}{lllllll}10-1 & 2\end{array}\right]$} \\
\hline & Market development forecasting & [13] \\
\hline & Sales forecasting & [14-19] \\
\hline & Price elasticity modeling & [20] \\
\hline & Target marketing & {$[15,21-22]$} \\
\hline & Customer satisfaction as sessment & {$[23]$} \\
\hline & Customer loyalty and retention & {$[24-26]$} \\
\hline & Market segmentation & {$[27-30]$} \\
\hline & Customer behavior analysis & {$[31-32]$} \\
\hline & Brand analysis & {$[27,33]$} \\
\hline & Market basket analysis & [34] \\
\hline & Storage layout & [35] \\
\hline & Customer gender analysis & [36] \\
\hline & Market orientation and performance & [6] \\
\hline & Marketing strategies, strategic planning and performance & {$[3,37-39]$} \\
\hline & Marketing data mining & {$[40]$} \\
\hline & Marketingmargin estimation & {$[41]$} \\
\hline & New product acceptance research & [42] \\
\hline & Consumer choice prediction & [43] \\
\hline & Market share forecasting & [44] \\
\hline Business Area & Problem type & Reference \\
\hline \multirow{14}{*}{ Finance and Accounting } & Financial health prediction & {$[3,47-49]$} \\
\hline & Compensation assessment & {$[50-51]$} \\
\hline & Bankruptcy classification & {$[52-57]$} \\
\hline & Analytical review process & {$[58-59]$} \\
\hline & Credit scoring & {$[60-62]$} \\
\hline & Signature verification & {$[48,63]$} \\
\hline & Risk assessment & {$[64]$} \\
\hline & Forecasting & {$[65-66]$} \\
\hline & Stock trend classification & [67-69] \\
\hline & Bond rating & {$[70-71]$} \\
\hline & Interest rate structure analysis & {$[72]$} \\
\hline & Mutual found selection & [73] \\
\hline & Compensation assessment & {$[50-51]$} \\
\hline & Credit evaluation & [74-79] \\
\hline Business Area & Problem type & Reference \\
\hline \multirow[t]{8}{*}{ Manufacturing and production } & Engineering design & {$[80-84]$} \\
\hline & Quality control & [85-89] \\
\hline & Storage design & {$[35]$} \\
\hline & Inventory control & {$[90-92]$} \\
\hline & Supply chain management & {$[93-95]$} \\
\hline & Demand forecasting & {$[96-100]$} \\
\hline & Monitoring and diagnosis & {$[101-105]$} \\
\hline & Process selection & {$[80,106-109]$} \\
\hline Business Area & Problem type & Reference \\
\hline $\begin{array}{l}\text { Strategic management and business } \\
\text { policy }\end{array}$ & $\begin{array}{l}\text { Strategic planning and } \\
\text { performance Assessing } \\
\text { decision making }\end{array}$ & $\begin{array}{l}{[3,37,39,} \\
111-114] \\
{[114-120]}\end{array}$ \\
\hline
\end{tabular}




\section{Conclusion}

Here in this paper we have tried to survey the reported works in the area of applications of ANN to different problems of management. Neural networks are shown to have matured to the point of offering practical solutions in many of their applications. However there is a clear deficit of more complete work describing neural network models. follows:

The various advantages and disadvantages of using the artificial neural networks can be summarized as

\section{Advantages:}

- The ANN models can provide highly accurate results in comparison with regression models.

- The significance and accuracy of these models can be assessed using the traditional statistical measures of mean squared error.

- These models automatically handle variable interactions.

- ANN models can be easily updated and hence are suitable for dynamic environment.

- Artificial neural networks have associative ability i.e. once developed; an ANN is generally robust to missing or inaccurate data.

- ANN is a reliable tool for predicting the determinants of relationship quality.

\section{Disadvantages:}

- No method has yet been devised to determine the significance of independent inputs in a neural network directly.

- It is difficult to state the results in simple precise analytical model statement.

- ANN learning process can be very time consuming.

- If the environment changes, the network must be reconstructed.

\section{References:}

[1] White, H., 1989. Neural Network Learning and Statistics. AI Expert, 4(12): 48-82.

[2] Ainscough, T.L. and J.E. Aronson, 1999. An empirical investigation and comparison of neural networks and regression for scanner data analysis. Journal of Retailing and Consumer Services, 6: 205-217.

[3] St. John, C.H., N. Balakrishnan and J.O. Fiet, 2000. Modeling the relationship between corporate strategy and wealth creation using neural networks. Computers and Operations Research, 27: 1077-1092.

[4] Smith, K. and J. Gupta, 2002. Neural networks in Business; techniques and applications. 1. USA: IDEA GROUP PUBLISHING. 271.

[5] Haykin, S.S., 2009. Neural networks and learning machines. Vol. 10. 2009: Prentice Hall Upper Saddle River, NJ.

[6] Silva, M., et al., 2007. Market orientation and performance: modelling a neural network. European Journal of Marketing, 43(3/4): 421-437.

[7] Chien, T.W., et al., 1999. A neural networks-based approach for strategic planning. Information and Management, 35: 357-364

[8] Fischer, M., G. Dorffiner and K. Hornik, 1996. Adaptive Information systems and Modelling in Economics and Management Science, in Austrian Research Foundation.

[9] Krycha, K.A. and U. Wagner, 1999. Applications of artificial neural networks in management science: a survey. Journal of Retailing and Consumer Services, 6: 185-203.

[10] Bounds, D. and D. Ross, 1997. Forecasting customer response with neural networks, in Handbook of Neural Computation, pp: 1-7.

[11] Moutinho, L., et al., 1994. Neural networks in marketing, in Computer Modelling and Expert Systems in Marketing, L. In Moutinho, Editor, Routledge: New York, pp: 191-212.

[12] Dasgupta, C.G., G.S. Dispensa and S. Ghose, 1994. Comparing the predictive performance of a neural network model with some traditional market response models. International Journal of Forecasting, 10(2): 235-244.

[13] Wang, S., An adaptive approach to market development forecasting. Neural Computing and Applications, 1999. 8(1): p. 3-8.

[14] Kong, J.H.L. and G.M. Martin, 1995. A backpropagation neural network for sales forecasting. in Proceedings IEEE International Conference on Neural Networks.

[15] Venugopal, V. and W. Baets, 1994. Neural networks and their applications in marketing management. Journal of Systems Management, pp: 16-21.

[16] Chang, P.C., C.H. Liu and C.Y. Fan, 2009. Data clustering and fuzzy neural network for sales forecasting: A case study in printed circuit board industry. Knowledge-Based Systems, 22(5): 344-355.

[17] Thomassey, S. and M. Happiette, 2007. A neural clustering and classification system for sales forecasting of new apparel items. Applied Soft Computing, 7(4): 1177-1187.

[18] Peter Zhang, G. and M. Qi, 2002. Predicting Consumer Retail Sales Using Neural Networks, in neural networks in Business: Techniqes and applications, IDEA GROUP PUBLISHING, pp: 26-40.

[19] Li, G.Q., S.W. Xu and Z.M. Li, 2010. Short-Term Price Forecasting For Agro-products Using Artificial Neural Networks. Agriculture and Agricultural Science Procedia, 1: 278-287.

[20] Gruca, T.S. and B.R. Klemz, 1998. Using neural networks to identify competitive market structures from aggregate market response data. Omega, 26(1): 49-62.

[21] Zahavi, J. and N. Levin, 1997. Applying neural computing to target marketing. Journal of Direct Marketing, 11: 76-93.

[22] Potharst, R., U. Kaymak and W. Pijls, 2002. Neural Networks for Target Selection in Direct Marketing, in Neural Networks in Business: techniques and applications, pp: 89-110.

[23] Temponi, C., Y.F. Kuo and H.W. Corley, 1999. A fuzzy neural architecture for customer satisfaction assessment. Journal of Intelligent and Fuzzy Systems, 7(2): 173-183. 
[24] Mozer, M.C. and R. Wolniewics, 2000. Predicting subscriber dissatisfaction and improving retention in the wireless telecommunication. IEEE Transactions on Neural Networks, 11(3): 690-696.

[25] Madden, G. and S. Savage, 1999. Subscriber churn in the Australian ISP market. Information Economics and Policy, 11(2): 195207.

[26] Smith, K.A., R.J. Willis and M. Brooks, 2000. An analysis of customer retention and insurance claim patterns using data mining: A case study. Journal of the Operational Research Society, 51(5): 532-541.

[27] Reutterer, T. and M. Natter, 2000. Segmentation based competitive analysis with MULTICLUS and topology representing networks. Computers and Operations Research, 27(11): 1227-1247.

[28] Vellido, A., P.J.G. Lisboa and K. Meehan, 1999. Segmentation of the online shopping market using neural networks. Expert Systems with Applications, 17(4): 303-314.

[29] Cardoso, M.G.M.S. and F. Moura-Pires, 2002. Segmentation of the Portuguese Clients of Pousadas de Portugal, in Neural Networks in Business: techniques and applications. IDEA GROUP PUBLISHING, pp: 70-88.

[30] Bloom, J.Z., 2005. MARKET SEGMENTATION: A Neural Network Application. Annals of Tourism Research, 32(1): 93-111.

[31] van Wezel, M.C., J.N. Kok and K. Sere, 1996. Determining the number of dimensions underlying customer-choices with a competitive neural network. in Proceedings of the IEEE International Conference on Neural Networks.

[32] Watkins, D., 1998. Discovering geographical clusters in a U.S. telecommunications company call detail records using Kohonen self organising maps. in Proceedings of the Second International Conference on the Practical Application of Knowledge Discovery and Data Mining.

[33] Balakrishnan, P.V.S., et al., 1996. Comparative performance of the FSCL neural net and K-means algorithm for market segmentation. European Journal of Operational Research, 93(2): 346-57.

[34] Evans, O.V.D., 1997. Discovering associations in retail transactions using neural networks. Icl Systems Journal, 12(1): 73-88.

[35] Su, C.T., 1995. Neural network system for storage layout design of warehouse, in Proceedings of the IASTED International Conference. Modelling and Simulation, pp: 573-575.

[36] Moutinho, L., F. Davies and B. Curry, 1996. The impact of gender on car buyer satisfaction and loyalty. Journal of Retailing and Consumer Sciences, 3(3): 135-144.

[37] Phillips, P.A., F.R. David and L. Moutinho, 2002. assessing the impact of market-focused and price-based strategies on performance. Journal of Market-Focused management, 5(3): 219.

[38] Phillips, P.A., F.M. Davis and 1. Mountinho, 2001. The interactive effects of strategic marketing planning and performance: a neural network analysis. Journal of Marketing management, 17: 159-182.

[39] Moutinho, L. and P.A. Phillips, 2002. the impact of strategic planning on the competitiveness, performance and effectiveness of bank branches: a neural network analysis International Journal of Bank Marketing, 20(3): 102-110.

[40] Ha, S.H. and S.C. Park, 1998. Application of data mining tools to hotel data mart on the Intranet for database marketing. Expert Systems With Applications, 15: 1-31.

[41] Mainland, D.D., 1998. Econometrics or neural networks-a study of marketing margins in the UK meat industry. Applied Economic Letters, 5(9): 593-597.

[42] Kumar, A., V.R. Rao and H. Soni, 1995. An empirical comparison of neural network and logistic regression models. Marketing Letters, 6(4): 251-263.

[43] West, P.M., P.L. Brockett and L.L. Golden, 1997. A comparative analysis of neural networks and statistical methods for predicting consumer choice. Marketing Science, 16(4): 370-391.

[44] Agrawal, D. and C. Schorling, 1996. Market share forecasting: An empirical comparison of artificial neural networks and multinomial logit model. Journal of Retailing, 72(4): 383-407.

[45] McNELIS, P.D., 2005. Neural Networks in Finance. Amsterdam: Elsevier Academic Press.

[46] Ji í, T., 2010. APPLICATION OF NEURAL NETWORKS IN FINANCE. Journal of Applied Mathematics, 3(3): $269-277$.

[47] Lacher, R.C., et al., 1995. A neural network for classifying the financial health of a firm. European Journal of Operational Research 85, 53, 65(85): 53-65.

[48] Abu-Rezq, A.N. and A.S. Tolba, 1999. Cooperative self-organizing maps for consistency checking and signature verification. Digital Signal Processing: A Review Journal, 9(2): 107-119.

[49] Mokhatab Rafiei, F., S.M. Manzari and S. Bostanian, 2011. Financial health prediction models using artificial neural networks, genetic algorithm and multivariate discriminant analysis: Iranian evidence. Expert Systems with Applications, 38(8): $10210-10217$.

[50] Borgulya, I., 1999. Two examples of decision support in the law. Artificial Intelligence and Law, 7(2-3): 303-321.

[51] Hancock, M.F., 1996. Estimating dollar value outcomes of Workers' Compensation claims using radial basis function networks, in Application of Neural Networks in Environment, Energy and Health, P. In Keller, Editor, World Scientific Publishing: singapore, pp: 199-208.

[52] Wilson, R. and R. Sharda, 1997. Business failure prediction using neural networks, in Encyclopedia of Computer Science and Technology. Marcel Dekker, Inc: New York, pp: 193-204.

[53] Olmeda, I. and E. Fernandez, 1997. Hybrid classifiers for financial multicriteria decision making: The case of bankruptcy prediction. Computational Economics, 10(4): 317-335.

[54] Jo, H., I. Han and H. Lee, 1997. Bankruptcy prediction using case-based reasoning, neural network and discriminant analysis. Expert Systems With Applications, 13(2): 97-108.

[55] Morris, R., 1997. Predicting failure: A failure in prediction. Accountancy, pp: 152-153.

[56] Piramuthu, S., H. Ravagan and M.J. Shaw, 1998. Using feature construction to improve the performance of neural networks. Management Science, 44(3): 416-430.

[57] Kiviluoto, K., 1998. Predicting bankruptcies with the self-organizing map. Neurocomputing, 21(1-3): 203-224.

[58] Coakley, J.R., 1995. Using pattern analysis methods to supplement attention-directing analytical procedures. Expert Systems With Applications, 9(4): 513-528.

[59] Coakley, J.R. and C.E. Brown, 1993. Artificial neural networks applied to ratio analysis in the analytical review process. Intelligent Systems in Accounting Finance and Management, 2: 19-39.

[60] West, D., 2000. Neural network credit scoring models. Computers and Operations Research, 27(11): 1131-1152.

[61] Long, J.A. and A. Raudys, 2000. Modelling company credit ratings using a number of classification techniques. in Fifteenth European Meeting on Cybernetics and Systems Research.

[62] Bassi, D. and C. Hernandez, 1997. Credit risk scoring: results of different network structures, preprocessing and self-organised clustering. Decision Technologies for Financial Engineering. in Fourth International Conference on Neural Networks in the Capital Markets.

[63] Ageenko, I.I., 1998. Neural networks for security in electronic banking. Edp Auditor Journal, 5: 25-28. 
[64] Garavaglia, S., 1996. Determination of systematic risk in U.S. businesses using Sammon's mapping and self-organizing maps, in World Congress on Neural Networks, International Neural Network Society. annual meeting, pp: 831-840.

[65] Leung, M.T., A.S. Chen and H. Daouk, 2000. Forecasting exchange rates using general regression neural networks. Computers and Operations Research, 27(11): 1093-1110.

[66] Grudnitski, G. and L. Osburn, 1993. Forecasting S and P and gold futures prices: an application of neural networks. Journal of Futures Markets, 13: 631-643.

[67] Saad, E.W., D.V. Prokhorov and D.C.I. Wunsch, 1998. Comparative study of stock trend prediction using time delay, recurrent and probabilistic neural networks. IEEE Transactions on Neural Networks, 9(6): 1456-1470.

[68] Cao, Q. and M.E. Parry, 2009. Neural network earnings per share forecasting models: A comparison of backward propagation and the genetic algorithm. Decision Support Systems, 47(1): 32-41.

[69] Mostafa, M.M., 2010. Forecasting stock exchange movements using neural networks: Empirical evidence from Kuwait. Expert Systems with Applications, 37(9): 6302-6309.

[70] Surkan, A.J. and Y. Xingren, 1991. Bond rating formulas derived through simplifying a trained neural network. in IEEE International Joint Conference on Neural Networks.

[71] Dutta, S. and S. Shenkar, 1993. Bond rating: a non-conservative application of neural networks, in Neural Networks in Finance and Investing, R.a.T. In Trippi, E., Editor. Probus Publishing Company: Chicago.

[72] Cottrell, M., et al. 1997. Simulating interest rate structure evolution on a long term horizon: A Kohonen map application. Decision Technologies for Financial Engineering. in Fourth International Conference on Neural Networks in the Capital Markets, singapore: World Scientific.

[73] Markets, singapore: World Scientific. Visual Explorations in Finance with Self-Organizing Maps. London: Springer-Verlag.

[74] Desay, V.S., J.N. Crook and G.A. Overstreet Jr., 1996. A comparison of neural networks and linear scoring models in the credit union environment. European Journal of Operational Research, 95: 24-37.

[75] Torsun, I.S., 1996. A neural network for a loan application scoring system. The New Review of Applied Expert Systems, 22 : 47-62.

[76] Arminger, G., D. Enache and T. Bonne, 1997. Analyzing credit risk data: A comparison of logistic discrimination classification tree analysis and feedforward networks. Computational Statistics, 12: 293-310.

[77] Glorfeld, L.W. and B.C. Hardgrave, 1996. An improved method for developing neural networks: the case of evaluating commercial loan creditworthiness. Computers and Operations Research, 23(10): 933-944.

[78] Hand, D.J. and W.E. Henley, 1997. Statistical classification methods in consumer credit scoring: A review. Journal of the Royal Statistical Society, 160(3): 523-541.

[79] Angelini, E., G. di Tollo and A. Roli, 2008. A neural network approach for credit risk evaluation. The Quarterly Review of Economics and Finance, 48(4): 733-755.

[80] Ding, L. and J. Matthews, 2009. A contemporary study into the application of neural network techniques employed to automate $\mathrm{CAD} / \mathrm{CAM}$ integration for die manufacture. Computers and Industrial Engineering, 57(4): 1457-1471.

[81] Wang, Q., 2007. Artificial neural networks as cost engineering methods in a collaborative manufacturing environment. International Journal of Production Economics, 109(1-2): 53-64.

[82] Hung, S.L. and J.C. Jan, 1999. Machine learning in engineering analysis and design: An integrated fuzzy neural network learning model. Computer-Aided Civil and Infrastructure Engineering, 14(3): 207219.

[83] Adeli, H. and C. Yeh, 1990. Neural network learning in engineering design. in International Neural Network Conference.

[84] Kulkarni, U.R. and M.Y. Kiang, 1995. Dynamic grouping of parts in flexible manufacturing systems-A self-organizing neural networks approach. European Journal of Operational Research, 84(1): 192-212.

[85] Dominguez, S., P. Campoy and R. Aracil, 1994. A neural network based quality control system for steel strip manufacturing. Annual Review in Automatic Programming, 19: 185-190.

[86] Köksal, G., I. Batmaz and M.C. Testik, 2009. A review of data mining applications for quality improvement in manufacturing industry. Expert Systems with Applications, In Press, Corrected Proof.

[87] Pacella, M., Q. Semeraro and A. Anglani, 2004. Manufacturing quality control by means of a Fuzzy ART network trained on natural process data. Engineering Applications of Artificial Intelligence, 17(1): 83-96.

[88] Sciuto, G., et al., 2009. Quality control of daily rainfall data with neural networks. Journal of Hydrology, 364(1-2): 13-22.

[89] Chen, F.L. and S.F. Liu, 2000. A neural-network approach to recognize defect spatial pattern in semiconductor fabrication. IEEE Transactions on Semiconductor Manufacturing, 13(3): 366-373.

[90] Lin, Y.H., J.R. Shie and C.H. Tsai, 2009. Using an artificial neural network prediction model to optimize work-in-process inventory level for wafer fabrication. Expert Systems with Applications, 36(2, Part 2): 3421-3427.

[91] Gumus, A.T. and A.F. Guneri, 2009. A multi-echelon inventory management framework for stochastic and fuzzy supply chains. Expert Systems with Applications, 36(3, Part 1): 5565-5575.

[92] Gumus, A.T., A.F. Guneri and F. Ulengin, 2010. A new methodology for multi-echelon inventory management in stochastic and neuro-fuzzy environments. International Journal of Production Economics, 128(1): 248-260.

[93] Ko, M., A. Tiwari and J. Mehnen, 2010. A review of soft computing applications in supply chain management. Applied SoftComputing, 10(3): 661-674.

[94] Chaharsooghi, S.K., J. Heydari and S.H. Zegordi, 2008. A reinforcement learning model for supply chain ordering management: An application to the beer game. Decision Support Systems, 45(4): 949-959.

[95] Yoo, J.S., S.R. Hong and C.O. Kim, 2009. Service level management of nonstationary supply chain using direct neural network controller. Expert Systems with Applications, 36(2, Part 2): 3574-3586.

[96] Efendigil, T., S. Önüt and C. Kahraman, 2009. A decision support system for demand forecasting with artificial neural networks and neuro-fuzzy models: A comparative analysis. Expert Systems with Applications, 36(3, Part 2): 6697-6707.

[97] Abdel-Aal, R.E., 2008. Univariate modeling and forecasting of monthly energy demand time series using abductive and neural networks. Computers and Industrial Engineering, 54(4): 903-917.

[98] González-Romera, E., M.A. Jaramillo-Morán and D. Carmona-Fernández, 2008. Monthly electric energy demand forecasting with neural networks and Fourier series. Energy Conversion and Management, 49(11): 3135-3142.

[99] Tsai, T.H., C.K. Lee and C.H. Wei, 2009. Neural network based temporal feature models for short-term railway passenger demand forecasting. Expert Systems with Applications, 36(2, Part 2): 3728-3736.

[100] Carbonneau, R., K. Laframboise and R. Vahidov, 2008. Application of machine learning techniques for supply chain demand forecasting. European Journal of Operational Research, 184(3): 1140-1154.

[101] Hanomolo, A., 1999. A neural classifier for fault diagnosis: An entropy approach. in Third International Conference on Industrial Automation. 
[102] Fast, M. and T. Palmé, 2010. Application of artificial neural networks to the condition monitoring and diagnosis of a combined heat and power plant. Energy, 35(2): 1114-1120.

[103] Rusinov, L.A., et al., 2009. Fault diagnosis in chemical processes with application of hierarchical neural networks. Chemometrics and Intelligent Laboratory Systems, 97(1): 98-103.

[104] Mitoma, T., H. Wang and P. Chen, 2008. Fault diagnosis and condition surveillance for plant rotating machinery using partiallylinearized neural network. Computers and Industrial Engineering, 55(4): 783-794.

[105] Wu, J.D. and C.H. Liu, 2008. Investigation of engine fault diagnosis using discrete wavelet transform and neural network. Expert Systems with Applications, 35(3): 1200-1213.

[106] Lee, C.C. and C. Ou-Yang, 2009. A neural networks approach for forecasting the supplier's bid prices in supplier selection negotiation process. Expert Systems with Applications, 36(2, Part 2): 2961-2970.

[107] Aksoy, A. and N. Öztürk, 2011. Supplier selection and performance evaluation in just-in-time production environments. Expert Systems with Applications, 38(5): 6351-6359.

[108] Yu, J., L. Xi and X. Zhou, 2009. Identifying source(s) of out-of-control signals in multivariate manufacturing processes using selective neural network ensemble. Engineering Applications of Artificial Intelligence, 22(1): 141-152.

[109] Pathumnakul, S., K. Piewthongngam and A. Apichottanakul, 2009. A neural network approach to the selection of feed mix in the feed industry. Computers and Electronics in Agriculture, 68(1): 18-24.

[110] Grant, R.M., 2003. Strategic planning in a turbulent environment: evidence from the oil majors. Strategic Management Journal, 491: 517.

[111] Chien, T.W., et al., 1999. A neural networks-based approach for strategic planning. Information and Management, 35(6): 357-364.

[112] Montagno, R., R.S. Sexton and B.N. Smith, 2002. Using neural networks for identifying organizational improvement strategies. European Journal of Operational Research, 142(2): 382-395.

[113] Stavrou, E.T., C. Charalambous and S. Spiliotis, 2007. Human resource management and performance: A neural network analysis. European Journal of Operational Research, 181(1): 453-467.

[114] Biscontri, R. and K. Park, 2000. An empirical evidence of the financial performance of lean production adoption: A self-organizing neural networks approach. in International Joint Conference on Neural Networks.

[115] Azadeh, A., M. Saberi and M. Anvari, 2010. An integrated artificial neural network algorithm for performance assessment and optimization of decision making units. Expert Systems with Applications, 37(8): 5688-5697.

[116] Mazurowski, M.A., et al., Training neural network classifiers for medical decision making: The effects of imbalanced datasets on classification performance. Neural Networks. 21(2-3): 427-436.

[117] Wang, J. and B. Malakooti, 1992. A feedforward neural network for multiple criteria decision making. Computers and Operations Research, 19(2): 151-167.

[118] Wu, K.T. and F.C. Lin, 1999. Forecasting airline seat show rates with neural networks. in international Joint Conference on Neural Networks.

[119] Sroczan, E., Neural network applied for simulation a strategy of dispatching and development of the electrical power system. in 9 th European Simulation Symposium.

[120] Lin, L., et al., 2000. Research of supply chain decision support system based on self-organization, in 3rd World Congress on Intelligent Control and Automation, pp: 1926-1930.

[121] Wyatt, R., 1995. Using neural networks for generic strategic planning. in International Conference on Artificial Neural Nets and Genetic Algorithms. Springer-Verlag.

[122] Parkinson, E.L., et al., 1994. integration architecture of expert systems, neural networks, hypertext and multimedia can provide competitive opportunities for industrial applications. Computers and Industrial Engineering, 27: 260-272.

[123] Venugopal, V. and W. Baets, 1994. Neural Networks and Statistical Techniques in Marketing Research: A Conceptual Comparison. Marketing intelligence and planning, 12(7): 30-38.

[124] Bejou, D., B. Warry and T.M. Ingram, 1996. determinants of relationship quality: an artificial neural network analysis. journal of business research, 36: 137-143. 